\title{
Biphotonic holographic gratings in azobenzene polyesters: Surface relief phenomena and polarization effects
}

\author{
Sánchez, C.; Alcalá, R.; Hvilsted, Søren; Ramanujam, P.S.
}

Published in:

Applied Physics Letters

Link to article, DOI:

10.1063/1.1290604

Publication date:

2000

Document Version

Publisher's PDF, also known as Version of record

Link back to DTU Orbit

Citation (APA):

Sánchez, C., Alcalá, R., Hvilsted, S., \& Ramanujam, P. S. (2000). Biphotonic holographic gratings in azobenzene polyesters: Surface relief phenomena and polarization effects. Applied Physics Letters, 77(10), 1440-1442. https://doi.org/10.1063/1.1290604

\section{General rights}

Copyright and moral rights for the publications made accessible in the public portal are retained by the authors and/or other copyright owners and it is a condition of accessing publications that users recognise and abide by the legal requirements associated with these rights.

- Users may download and print one copy of any publication from the public portal for the purpose of private study or research.

- You may not further distribute the material or use it for any profit-making activity or commercial gain

- You may freely distribute the URL identifying the publication in the public portal 


\title{
Biphotonic holographic gratings in azobenzene polyesters: Surface relief phenomena and polarization effects
}

\author{
C. Sánchez and R. Alcaláa) \\ Departamento de Física de la Materia Condensada, ICMA, Universidad de Zaragoza-CSIC, 50009, \\ Zaragoza, Spain
}

S. Hvilsted

Danish Polymer Centre, Department of Chemical Engineering, Technical University of Denmark, DK-2800 Lyngby, Denmark

P. S. Ramanujam

Risø National Laboratory, DK-4000 Roskilde, Denmark

(Received 1 May 2000; accepted for publication 10 July 2000)

\begin{abstract}
Biphotonic holographic gratings have been recorded in a side-chain azobenzene liquid crystalline polyester using a blue incoherent source and a He-Ne laser. Intensity gratings and the appearance of surface relief have been observed when two linearly polarized beams from a He-Ne laser are made to interfere on a film illuminated with blue light. Polarized holographic gratings are also created with two orthogonally circularly polarized He-Ne beams. All these gratings are stable in darkness but can be erased with blue light. (C) 2000 American Institute of Physics.

[S0003-6951(00)02436-0]
\end{abstract}

Azobenzene containing polymers have proven to be suitable materials for optical storage. Diffraction gratings recorded while using an intensity or polarization modulated pattern (from now on, intensity and polarization gratings, respectively) and the appearance of relief gratings have been observed in these materials by using coherent light in the region of $500 \mathrm{~nm} .{ }^{1-6}$ A biphotonic process was found in azobenzene polyesters which can be useful in holographic experiments. ${ }^{7,8}$ In this case, the holographic grating was written by an argon laser beam and was developed using a red $\mathrm{He}-\mathrm{Ne}$ laser beam. Another type of holographic storage has also been reported using coherent red light by means of biphotonic processes. ${ }^{9-12}$ In these processes, a blue incoherent light is used to sensitize the azo chromophores in the red region and recording is performed with a coherent red source. This allows diode lasers to be used which is important for photonic applications. However, while permanent intensity, polarization, and relief gratings have been stored using blue lasers, only intensity gratings have been previously produced, with red lasers, in these kinds of materials. Besides, these gratings produced with red light are not stable and disappear after a few hours. In this letter, we report on the study of holographic recording by means of biphotonic processes in an azo-containing liquid crystalline polyester (P6a12 in Ref. 13). Intensity and polarization gratings, as well as surface relief, are studied in this polymer under blue (incoherent) and red (coherent) light illumination.

The synthesis and characterization of this polyester has been published elsewhere. ${ }^{13}$ Films about $2 \mu \mathrm{m}$ thick were produced by spin coating from a solution of the polymer in chloroform. Before performing the experiments, the films were heated at $80^{\circ} \mathrm{C}$ (well above the glass transition and the mesophase range of the polymer) in order to erase any ther-

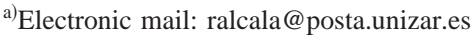

mal history or previously induced effects. Afterwards, the films were cooled down to room temperature (RT) by putting them on a metallic plate. All the experiments were performed at RT.

A scheme of the experimental setup used in the holographic measurements is shown in Fig. 1. The unpolarized light of a $150 \mathrm{~W}$ Xe lamp is passed through a bandpass filter (between 350 and $450 \mathrm{~nm}$ ) and focused on the sample. The power of this light in the film was about $30 \mathrm{~mW} / \mathrm{cm}^{2}$. Two beams $\left(I_{1}\right.$ and $\left.I_{2}\right)$ from a linearly polarized $\mathrm{He}-\mathrm{Ne}$ laser $(633 \mathrm{~nm})$ were made to interfere on the film. Both had the same power ( $6 \mathrm{~mW}$ distributed in a $4 \mathrm{~mm}^{2}$ spot) and their polarization state could be modified by insertion of wave retarders. The angle of intersection of the two beams was $3.6^{\circ}$ giving place to a grating with 100 lines $/ \mathrm{mm}$. To follow the evolution of the recorded gratings, the self-diffracted light was measured with a Si detector. We denote by $I_{i, j}$ the self-diffracted beams where the first subscript indicates which is the incident beam diffracted and the second one; the diffraction order. Thus, $I_{1,+1}$ denotes the order; +1 coming from the $I_{1}$ beam.

In our first experiment, the two $\mathrm{He}-\mathrm{Ne}$ beams were $s$ polarized (polarization vector perpendicular to the incidence plane of the light). In this way, the red light intensity was modulated over the surface of the film (intensity grating).

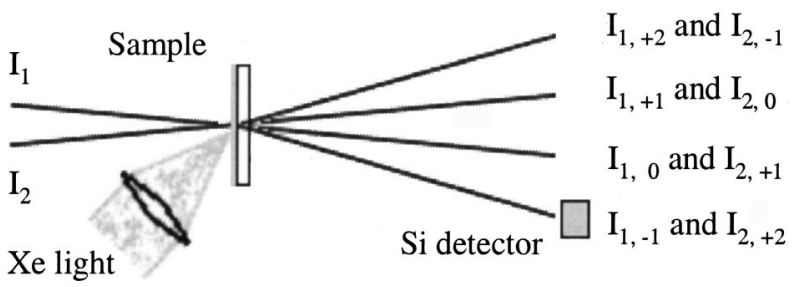

FIG. 1. Biphotonic holographic setup. Geometry of the recording ( $I_{1}$ and $\left.I_{2}\right)$ and self-diffracted beams $\left(I_{i, j}\right)$. 


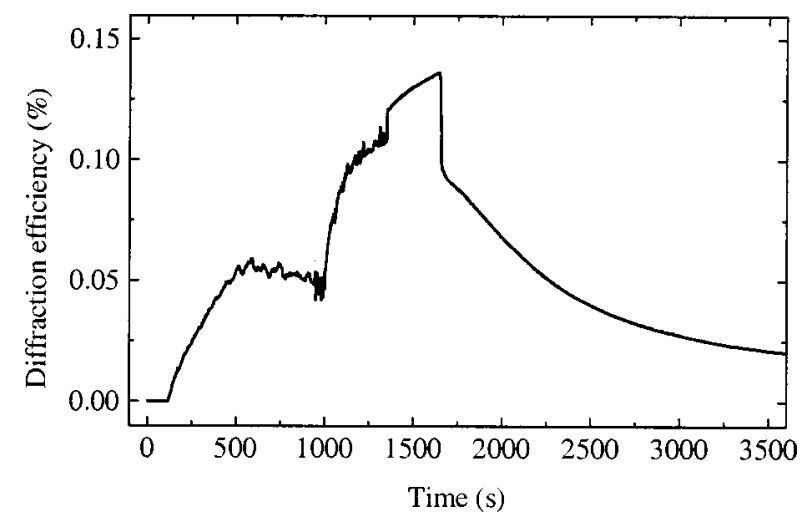

FIG. 2. Diffracted power as a function of time. At $t=0 \mathrm{~s}$ blue light is turned on; at $t=120 \mathrm{~s}$ two $\mathrm{He}-\mathrm{Ne}$ beams ( $\mathrm{s}$ polarized) are turned on; at $t=1000 \mathrm{~s}$ blue light is turned off; at $t=1350 \mathrm{~s}$ one $\mathrm{He}-\mathrm{Ne}$ is blocked; at $t=1650 \mathrm{~s}$ blue light is turned on again.

The detector was placed in such a way that, when the two beams $\left(I_{1}\right.$ and $\left.I_{2}\right)$ were open, the intensity detected is a superposition of the first order $I_{1,-1}$ of $I_{1}$ and the second order $I_{2,+2}$ of $I_{2}$. Figure 2 shows the time evolution of this signal. No diffraction was observed before irradiation with the Xe lamp. At $t=0$, only the Xe lamp was turned on and no signal was detected. After $120 \mathrm{~s}$, the two $\mathrm{He}-\mathrm{Ne}$ beams were turned on and the intensity began to grow with time. At $t=1000 \mathrm{~s}$, the Xe lamp was turned off and after a fast increase, the signal continued to grow more slowly. At $t=1350$ $\mathrm{s}$, the $I_{2}$ beam was blocked and then only the $I_{1,-1}$ diffracted light was detected. An instantaneous increase of the signal was followed by a continuous increase, despite the absence of intensity modulation in the film. Finally, and in order to optically erase the grating, the Xe lamp was switched on again at $t=1650 \mathrm{~s}$. The diffraction efficiency decreased in 10 $\mathrm{s}$ by about $30 \%$ and then the decrease continued more slowly until the grating was completely erased.

Besides the diffraction efficiency, the surface relief induced by biphotonic processes was investigated using a profilometer (DEKTAK). Before the holographic recording, the surface of the films was smooth and did not show any periodic feature. After the holographic grating was recorded, the surface of the polymer film showed a regularly spaced relief structure with the period of the grating as shown in Fig. 3.

Optical storage in azobenzenes is associated with light induced molecular reorientations due to trans-cis-trans isomerization processes. Although these processes are not

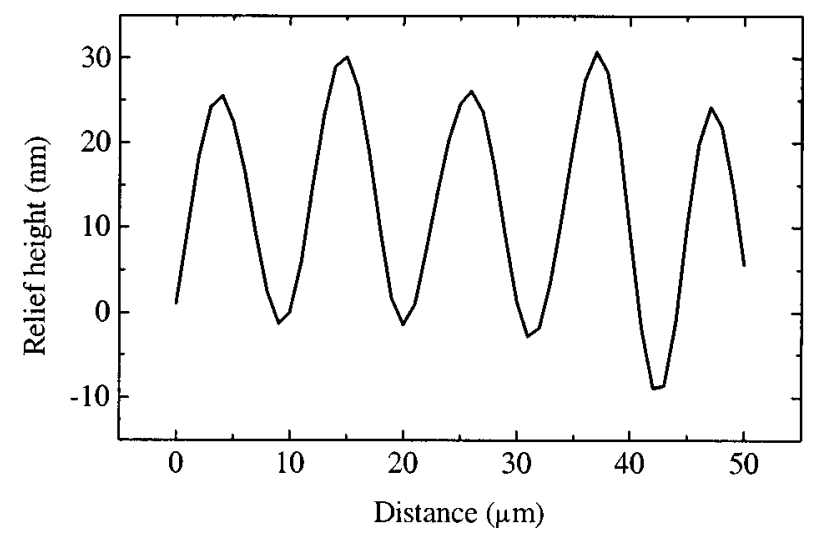

FIG. 3. Relief height of a grating recorded with $s-s$ polarization. Downloaded 10 Feb 2010 to 192.38.67.112. Redistribution subje fully understood, it is known that irradiation in the blue region induces transitions between the trans and cis states of the molecule. ${ }^{2,3}$ The thermally stable trans state has an absorption spectrum with an intense maximum in the UV region due to a $\pi-\pi^{*}$ transition and a weak maximum in the blue due to an $n-\pi^{*}$ transition. After irradiation in these maxima, the trans molecule can isomerize to the cis state. Unlike the trans state, the cis isomer is not thermally stable and undergoes a transition back to the trans state. A lifetime of $\sim 2 \mathrm{~h}$ has been estimated for the cyanoalkoxi substituted chromophore of our polyester. ${ }^{8}$ In addition, the trans state can be reached by optical excitation in the absorption bands of the cis isomer. It is known that the red light of a $\mathrm{He}-\mathrm{Ne}$ laser causes cis to trans isomerization. ${ }^{8}$ It has been proposed that the trans molecules produced in this way lay preferentially in the polarization plane of the $\mathrm{He}-\mathrm{Ne}$ laser beam. ${ }^{14}$ Before irradiation with the Xe lamp, all the molecules are in the trans state and no effect from the red light is observed. Exposure to blue light induces isomerizations between trans and cis states so that the cis population increases and the film becomes sensitive to red light.

As previously mentioned, several authors have investigated the formation of intensity gratings in azo doped polymers using biphotonic processes. They have explained it in terms of a spatial modulation of the isomer populations induced by the interference of the two He-Ne laser beams. ${ }^{9-11}$ The growth of the diffraction efficiency observed in our experiments when the two $\mathrm{He}-\mathrm{Ne}$ beams and the Xe lamp are present could be explained using the same model. When the Xe lamp is switched off, only cis to trans isomerization takes place in the illuminated areas and a reinforcement of the contrast between both populations would occur. When the $\mathrm{He}-\mathrm{Ne}$ beam $I_{2}$ is blocked, a sharp increase of the signal is observed. This can be attributed to the fact that in the presence of the two $\mathrm{He}-\mathrm{Ne}$ beams, we detect the interference of two coherent diffracted orders: the first order $I_{1,-1}$ of $I_{1}$ and the second order $I_{2,+2}$ of $I_{2}$, and the resulting intensity can be lower than that of $I_{1,-1}$ alone, that being the one detected with only one $\mathrm{He}-\mathrm{Ne}$ beam. On the other hand, when only this beam is present, there is no modulation of the red light intensity across the film, but a slow and long lasting growth of the diffracted intensity $I_{1,-1}$ is observed. A similar growth is observed if both $I_{1}$ and $I_{2}$ are blocked together. Besides, these intensities do not decrease after several days at RT indicating that a stable grating has been recorded. The increase of the diffracted intensity both in the dark or under illumination with only one $\mathrm{He}-\mathrm{Ne}$ beam cannot be understood in terms of a modulation of cis and trans populations because a decrease of the modulation would be expected in both cases. Furthermore, the gratings due to this modulation would disappear when all the cis molecules revert back to the trans state.

In order to explain our results, we have taken into account that polarized red light gives place to a cis-trans isomerization with the trans molecules preferentially parallel to the polarization direction of the light. ${ }^{14}$ When the two $\mathrm{He}-\mathrm{Ne}$ beams are present, this reorientation in the illuminated regions contributes to a change in the refractive index and, consequently, a phase diffraction grating appears which increases efficiency with time. To account for the growth in
to AlP license or copyright; see http://apl.aip.org/apl/copyright.jsp 


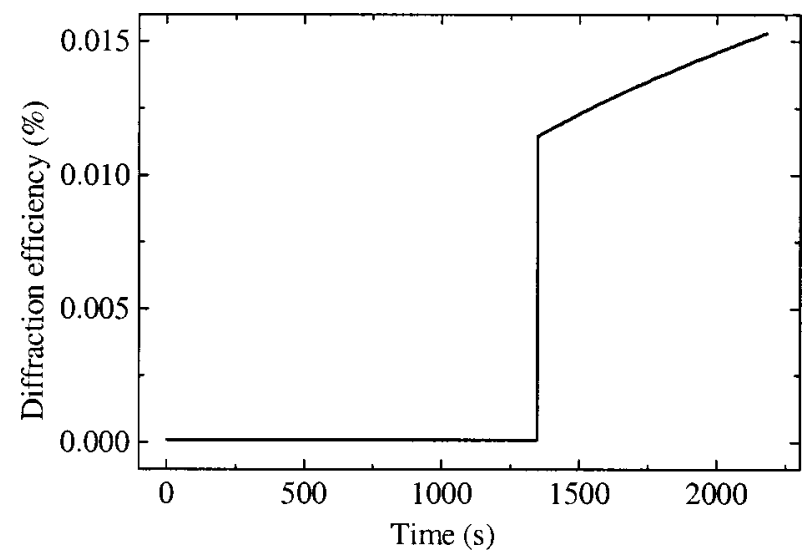

FIG. 4. Diffracted power as a function of time of a grating recorded using two orthogonally circularly polarized $\mathrm{He}-\mathrm{Ne}$ beams. The detector is blocked until $t=1350 \mathrm{~s}$.

darkness or with only one $\mathrm{He}-\mathrm{Ne}$ beam, we propose that the trans molecules initially oriented by the red light act as seeds for aggregation and orientation of the surrounding trans molecules and of those produced by back isomerization from the cis state. The liquid crystalline structure of our polymer, with strong cooperative interactions among the molecules, can strengthen the influence of aggregation and reorientation processes with respect to amorphous polymers previously studied. ${ }^{9-12}$ Those processes can give place to an increase of the diffracted light and to a relief grating as observed in our surface relief experiments. A similar mechanism has been proposed to explain some of the phenomena observed in gratings induced with coherent blue light. ${ }^{15}$ Finally, we will comment on the erasing process of the gratings. The fast decay observed in the first $10 \mathrm{~s}$ is similar to the one observed in polarization gratings in which no surface relief has been found. Because of this, we propose that this fast decay can be associated with a randomization of the molecules induced by the blue light while the slow second step can be due to the erasing of the relief gratings. More experiments to clear up this point are in progress.

To check the influence of red light polarization on the production of gratings using biphotonic processes, we have tried to induce polarization gratings in our P6a12 polymer. Two orthogonally circularly polarized $\mathrm{He}-\mathrm{Ne}$ beams (lefthand side to right-hand side configuration) have been made to overlap on the film. In this case, the light intensity is constant but the resultant linear polarization is periodically modulated. Following the same procedure as in the previous experiments, no signal is detected. However when the $I_{2}$ beam is blocked, the $I_{1,+1}$ order can be seen by the naked eye, while the $I_{1,-1}$ order is not observed. This strong selectivity with respect to the polarization of the reconstructing beam is typical of these kinds of polarization gratings. ${ }^{16}$ Figure 4 shows the evolution of the $I_{1,+1}$ order of diffraction. As this is superimposed to the zero order of the $I_{2}$ beam, the detector is screened until the $I_{2}$ beam is blocked at $t=1350 \mathrm{~s}$. As with the intensity gratings, an increase of the diffracted intensity with time is observed in the polarization gratings when the film is either illuminated with a single $\mathrm{He}-\mathrm{Ne}$ beam or kept in darkness for several hours. Afterwards, this intensity remains stable. Besides, no appreciable relief was observed in the surface of the polarization gratings recorded. This is supported by the absence of the $I_{1,-1}$ order in the left-hand side to right-hand side configuration. Fast erasing (about $10 \mathrm{~s}$ ) is achieved by switching on the Xe lamp.

These facts can also be explained by considering the orientation of the trans molecules parallel to the polarization of the red light (which induces the cis-trans isomerization) as well as the interaction among trans molecules, proposed for intensity gratings. The relief grating has been associated with the attraction among parallel molecules and, in this case, the molecular orientation changes across the film. The lack of relief can also account for the fast erasing of these gratings with blue light, in contrast to the behavior observed in intensity gratings. Surface relief has also been observed in films irradiated with blue light and subsequent irradiation with a $\mathrm{He}-\mathrm{Ne}$ laser in a transmission mask experiment. ${ }^{17}$

In conclusion, we have reported on the recording of stable (but erasable) holographic gratings (both intensity and polarization ones) in an azobenzene polyester by means of biphotonic processes. Surface relief gratings have also been induced with a $\mathrm{He}-\mathrm{Ne}$ laser. A tentative explanation has been given which accounts for the observed storage and erasing processes.

The financial support from the CICYT, Spain, under the project MAT99-1009-C02 is gratefully acknowledged. Support by the European Commission in the COST Action 518 framework is also acknowledged.

${ }^{1}$ M. Eich and J. H. Wendorff, J. Opt. Soc. Am. B 7, 1428 (1990).

${ }^{2}$ R. H. Berg, S. Hvilsted, and P. S. Ramanujam, Nature (London) 383, 505 (1996).

${ }^{3}$ P. Rochon, J. Gosselin, A. Natansohn, and S. Xie, Appl. Phys. Lett. 60, 4 (1992).

${ }^{4}$ A. Natansohn, P. Rochon, J. Gosselin, and S. Xie, Macromolecules 25, 2268 (1992).

${ }^{5}$ D. Y. Kim, S. K. Tripathy, L. Li, and J. Kumar, Appl. Phys. Lett. 66, 1166 (1995)

${ }^{6}$ N. K. Viswanathan, D. Y. Kim, S. Bian, J. Williams, W. Liu, L. Li, L. Samuelson, J. Kumar, and S. K. Tripathy, J. Mater. Chem. 9, 1941 (1999).

${ }^{7}$ P. S. Ramanujam, S. Hvilsted, and F. Andruzzi, Appl. Phys. Lett. 62, 1041 (1993).

${ }^{8}$ P. S. Ramanujam, S. Hvilsted, I. Zebger, and H. W. Siesler, Macromol. Rapid Commun. 16, 455 (1995).

${ }^{9}$ H. Bach, K. Anderle, Th. Fuhrmann, and J. H. Wendorff, J. Phys. Chem. 100, 4135 (1996).

${ }^{10}$ P. Wu, B. Zou, X. Wu, J. Xu, X. Gong, G. Zhang, G. Tang, and W. Chen, Appl. Phys. Lett. 70, 1224 (1997).

${ }^{11}$ P. Wu, L. Wang, J. Xu, B. Zou, X. Gong, G. Zhang, G. Tang, and W. Chen, Phys. Rev. B 57, 3874 (1998).

${ }^{12} \mathrm{P}$. Wu, X. Wu, L. Wang, J. Xu, B. Zou, X. Gong, and W. Huang, Appl. Phys. Lett. 72, 418 (1998).

${ }^{13}$ S. Hvilsted, F. Andruzzi, C. Kulinna, H. W. Siesler, and P. S. Ramanujam, Macromolecules 28, 2172 (1995).

${ }^{14}$ C. Kulinna, I. Zebger, S. Hvilsted, P. S. Ramanujam, and H. W. Siesler, Macromol. Symp. 83, 169 (1994).

${ }^{15}$ P. S. Ramanujam, N. C. R. Holme, and S. Hvilsted, Appl. Phys. Lett. 68, 1329 (1996).

${ }^{16}$ L. Nikolova and T. Todorov, Opt. Acta 31, 579 (1984).

${ }^{17}$ C. Sánchez, R. Alcalá, S. Hvilsted, and P. S. Ramanujam (unpublished). 